\title{
A case of twin reversed arterial perfusion (TRAP) sequence in a monochorionic diamniotic triplet pregnancy with two acardiac fetuses
}

\author{
J. Stuart May ${ }^{1}$, Susan Lanni ${ }^{2}$, J oe D. Jakowski ${ }^{3}$ \\ 1. Virginia Commonwealth University, School of Medicine, Richmond, VA, USA. 2. Department of Obstetrics and \\ Gynecology, VCU Health, Richmond, VA, USA. 3. Department of Pathology, VCU Health, Richmond, VA, USA
}

Correspondence: Joe D. Jakowski. Address: Department of Pathology, VCU Health, Richmond, VA, USA. Email: joseph.jakowski@vcuhealth.org

Received: March 11, 2016

Accepted: June 1, 2016

Online Published: June 16, 2016

DOI : $10.5430 /$ ijdi.v3n2p59

URL: http://dx.doi.org/10.5430/ijdi.v3n2p59

\section{Abstract}

Background: Twin reversed arterial perfusion (TRAP) sequence is a rare anomaly of monochorionic twins involving artery-to-artery anastomoses resulting in a structurally normal "pump" twin that provides circulation to an acardiac twin in a retrograde fashion.

Case: Herein we report a rare case of a triplet gestation (TrGA) consisting of two conjoined acardiac TRAP recipients and one surviving normal pump fetus. The TRAP recipients were discordant for their anomalies. We know of only three similar case reports from the literature.

Conclusion: Characteristic ultrasound findings allow for the prenatal diagnosis of TRAP sequence and may allow prompt and appropriate treatment to improve the outcome of the pump twin.

\section{Keywords}

TRAP sequence, Triplet pregnancy, Acardia, Ultrasound

\section{I ntroduction}

Twin reversed arterial perfusion (TRAP) sequence is a rare anomaly that affects monochorionic twins. This clinical entity involves artery-to-artery anastomoses resulting in a structurally normal "pump" twin that provides circulation to an acardiac twin recipient in a retrograde fashion ${ }^{[1-4]}$. There are two theories regarding the etiology of TRAP sequence. The leading theory suggests that vascular anastomoses occur first between the twins or triplets. These anastomoses then cause increase arterial pressure and reversal of flow that leads to absence or maldevelopment of the fetal heart in the recipient twin. The second theory describes the primary defect as the absence of a fetal heart that results in the formation of anastomoses and reversed perfusion of the recipient twin ${ }^{[5,6]}$. Prior case studies have had discordant conclusions with regards to chromosomal errors as the possible etiologic factor of the TRAP sequence ${ }^{[7,8]}$. Despite the cause of the original defect, the pump twin can frequently progress in utero to high output congestive heart failure (CHF) which can cause intrauterine growth retardation, polyhydramnios, premature delivery, hydrops, liver dysfunction, hypoalbuminemia, or even death ${ }^{[2,6]}$. 
Regarding the acardiac fetal twin, four major types have been described according to the degree of abnormal development present ${ }^{[5,6,9]}$.

(1) Acardius acephalus - the most common type with a well-developed pelvis and lower limbs but notable for a lack of a head, thorax, and upper limbs.

(2) Acardius anceps - some form of head and/or neural structures with developed truncal structures and organs, without a heart.

(3) Acardius acormus - only the head with no truncal structures.

(4) Acardius amorphus - the least differentiated form - an unorganized mass of tissue with no discernable head or truncal structures.

\section{Case report}

A gravid 30-year-old woman (G2P1) with a history of a prior cesarean section was referred to us at 26 weeks and one day with an outside ultrasound (US) diagnosis of a triplet gestation with TRAP sequence. A repeat transabdominal US confirmed TRAP sequence using Doppler overlay to visualize "to and fro blood flow" at the umbilical cord insertion of the pump twin (see Figure 1A) which was noted to be in the cephalic presentation. This pump twin was anatomically normal by US with a composite gestational age of 26 weeks one day by measuring the biparietal diameter (see Figure 1B) with an estimated fetal weight of 937 grams and a volume of 2,790 $\mathrm{cm}^{3}$. Two recipient acardiac fetuses were identified with one larger than the other. The larger recipient had an anechoic space at the cephalad end of the spine, presumed to be an underdeveloped empty calvarium due to TRAP sequence anomaly versus postmortem liquefaction (see Figure 1C). The second smaller recipient twin had an identifiable spine encased in a mass of edematous tissues with neither a fetal heart nor a fetal cranium present (US image not shown). At 27 weeks and two days, the patient presented with contractions every three minutes and vaginal leakage of brown fluid. Evaluation at this time excluded rupture of membranes and she had a closed cervix. A limited US scan revealed a normal amniotic fluid index of $138 \mathrm{~mm}$, absence of hydrops fetalis, and positive fetal heart movement in the donor fetus (see Figure 1D). Close monitoring revealed no further cervical change and the patient was discharged home with close follow-up.

Figure 1. Transabdominal ultrasounds of the TRAP sequence triplet gestation. Doppler ultrasound overlay showing bidirectional flow in the umbilical cord (A). Donor twin at 26 weeks 1 day gestational age; measuring the biparietal diameter of one Hadlock measurement used to calculate the weight (B). Acardiac Twin B with an anechoic space at "cephalad" end of spine and two dimensions measurement for calculation of the twin-weight ratio (C). Measurement of the amniotic fluid index showing no polyhydramnios (D). Measuring the third dimension of acardiac Twin B for calculation of the twin-weight ratio (E)
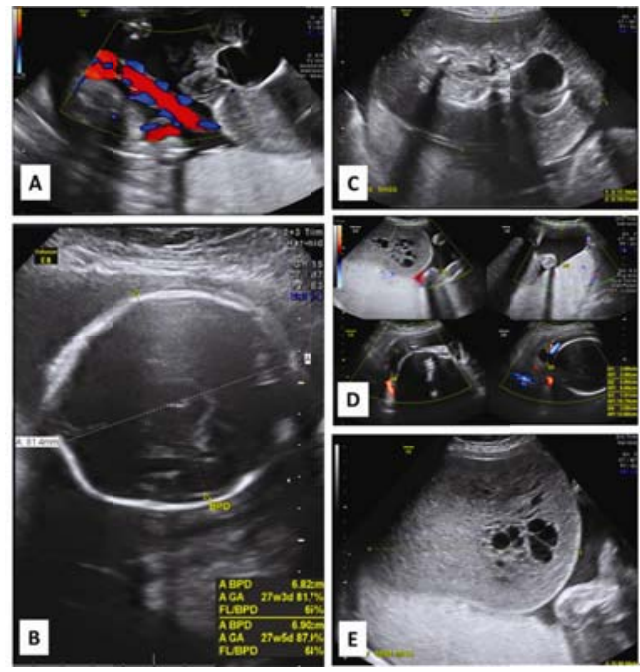

At 27 weeks and six days the patient was admitted in active preterm labor and a limited US performed was concerning for a compound presentation of the pump fetus. This presentation was confirmed by digital vaginal examination with the finding of the fetus' posterior hand alongside the fetal head. After ten minutes of active labor, maternal expulsive efforts were halted when the pump fetus' heart rate decelerated to $80 \mathrm{bpm}$. A repeat low transverse cesarean section was then 
performed with a T extension of the hysterotomy incision. The pump twin was delivered first - a 1,275 gram live-born male infant, with Apgars of two, two, and eight. The two acardiac recipient fetuses were then delivered piecemeal and sent off for radiographs and then to pathology with the placenta for gross and histologic evaluation.

At delivery, the pump twin had spontaneous respirations but soon required ventilation due to bradycardia and increased respiratory effort. The pump twin's hospital course was complicated by initial hypocalcemia, respiratory distress syndrome, and hypotension that all responded to resuscitative efforts. A transesophageal echocardiogram excluded congestive heart failure but there was left ventricular hypertrophy with normal left ventricular systolic function. Oral feeding was complicated by desaturations due to poor suck-swallow reflex; however, the pump twin was eventually weaned to oral feeds and gained weight. After a 14.5-week stay in the neonatal intensive care unit, the pump twin was discharged on a calcium channel blocker for hypertension.

$\mathrm{X}$-ray of the acardiac twins demonstrated two fetuses with underdeveloped osseous structures (see Figure 2A). The larger acardiac fetus had extensive soft tissue edema with gas present in the gastrointestinal tract (upper fetus in Figure 2A). There was incomplete development of the limb buds, a partially ossified skull, but no clear facial features that defined this larger recipient fetus as acardiac anceps. The smaller acardiac fetus had partial development of the limb buds with a tibia and femur present in one lower limb and only a femur present in the other lower limb (lower fetus in Figure 2A). There was complete lack of bones in the upper limb buds and gas was present in the gastrointestinal tract. An incompletely developed spine with complete absence of the skull defined this smaller recipient fetus as acardiac acephalus.
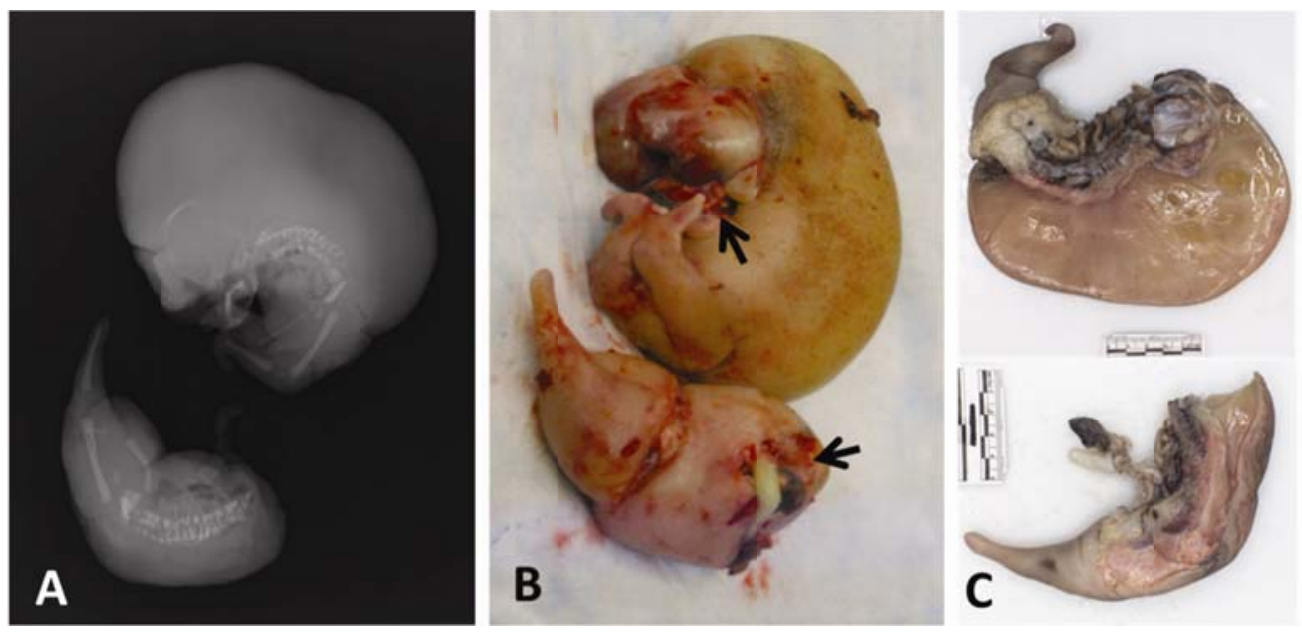

Figure 2. X-ray image demonstrating the osseous structures in both acardiac fetuses (A). Gross image of the two nonviable acardiac fetuses (B). Arrows indicate original site of attachment of both fetuses to each other. Cross-section of the fetuses (C). The larger fetus is acardius anceps consisting of a large mass of edematous tissue, cranial structures but without a face, absence of thoracic organs, and developed bowel loops, spine, pelvis, and lower limbs (top left panel C). The smaller fetus is acardius acephalus with absence of any cranial structures or thoracic organs and developed bowel loops, a single kidney, spine, partially developed pelvis, and fused lower limbs (lower left panel C)

On gross pathologic exam, the separate acardiac fetuses, which were divided at the time of delivery, were determined to be grossly consistent with conjoined fetuses with an area of disrupted soft tissue connection noted between the two (see Figure 2B). The total weight of both fetuses was 940 grams. A single trivascular umbilical cord measuring $5.5 \mathrm{~cm}$ in length by $0.7 \mathrm{~cm}$ in diameter was present in the umbilical area of the lager recipient. No external genitalia were identified in either recipient. An edematous tissue layer was present protruding from the posterior spine measuring up to $8.5 \mathrm{~cm}$ thick in the larger acardiac fetus (upper fetus Figure 2C). Both recipient fetuses displayed tan-pink, hair-bearing skin with two poorly formed jointed limbs extending from one pole - presumably the caudad pole. The larger acardiac fetus measured $18.0 \mathrm{~cm} \times 14.7 \mathrm{~cm} \times 6.0 \mathrm{~cm}$ with a cranial structure that had a $5.5 \mathrm{~cm} \times 4.5 \mathrm{~cm} \times 2.0 \mathrm{~cm}$ fluid-filled cystic space with yellow, semisolid neural tissue. This cranial space was surrounded by a partially calcified band of tissue resembling a 
rudimentary calvarium that was in continuity with the spinal column. The smaller acardiac fetus measured $14.2 \mathrm{~cm} \times$ $7.5 \mathrm{~cm} \times 6.0 \mathrm{~cm}$ and had a partially formed spinal column containing the spinal cord but no cranial or other neural structures (lower fetus Figure 2C). A pelvic girdle was present as well as multiple blind-ended loops of intestine. Each recipient fetus contained a midline kidney and possible gonadal structures. No liver, bladder, spleen, pancreas, or thoracic organs were identified in either acardiac recipient. Histology of the placenta was that of a monochorionic diamniotic placenta with focal acute chorionitis and gross and microscopic meconium staining.

\section{Discussion}

This particular presentation of TRAP sequence - two acardiac fetuses with one pump fetus in a triplet gestation - has been, to our knowledge, only described three times previously in the literature. Sanjaghsaz et al. ${ }^{[6]}$ referenced one prior case by Bolaji et al. ${ }^{[9]}$ and described one of their own. In their case, delivery at 35 weeks gestation resulted in two conjoined acardiac, acephalic twins and one normal pump female triplet, similar to the outcome of our case but with delivery near term. In 2011, Ventura et al. additionally described a case very similar to ours, however, the mother in this case went into spontaneous labor at 23 weeks and five days and US performed upon admission detected no fetal heart activity in the pump twin.

TRAP sequence is typically diagnosed by US during a second trimester anatomy screening and it then becomes the tool of choice for monitoring fetal progression and predicting prognosis. The major sonographic findings that aid in diagnosis of TRAP sequence include ${ }^{[10]}$ :

- A monochorionic twin pregnancy.

- $\quad$ Acardiac recipient twin with variable degrees of abnormal development.

- Pulse Doppler showing reverse flow in the umbilical cord artery of the acardiac recipient twin with a two vessels cord present in up to 70 percent of cases.

- Color Doppler demonstrating artery to artery anastomosis in the placental bed.

- A donor pump twin with a normal sonographic appearance or with fetal anomalies (in up to 9\% of cases) and/or associated with congestive heart failure and its sequela.

Wong and Sepulveda ${ }^{[11]}$ described a prenatal prognostic indicator for TRAP sequence that involves the relative size of the acardiac twin compared to its co-twin - the twin-weight ratio. This ratio refers to "the weight of the acardiac twin expressed as a percentage of the pump-twin weight”. A ratio greater than $70 \%$ correlates with a $90 \%$ incidence of preterm delivery, $40 \%$ incidence of polyhydramnios, and $30 \%$ incidence of pump twin CHF. This is compared to rates of $75 \%$, $30 \%$, and $10 \%$ with a twin-weight ratio of $<70 \%$. A ratio less than $50 \%$ correlated with $35 \%$ preterm delivery, $18 \%$ polyhydramnios, and $0 \%$ CHF. The twin-weight ratio in our TRAP case was calculated to be $74 \%$ and as predicted, the patient went into preterm labor. However, there was no polyhydramnios or CHF in the donor twin in our TRAP case. As a prognostic indicator, the twin-weight ratio has its limitations; most notably the highly inaccurate prenatal weight estimation in the acardiac twin due to its amorphous structure. Despite the limitations, the twin-weight ratio is still a clinically useful parameter as a possible prognostic indicator for TRAP sequence cases.

For continuing pregnancies, the presence or development of other poor prognostic indicators such as polyhydramnios, cardiac dysfunction and hydrops in the pump twin, or a relatively large weight of the acardiac twin are indications for prenatal treatment. These treatment modalities are directed toward improving the outcome for the pump twin and include medical management, which is beyond the scope of this current discussion, and target occlusion of the umbilical cord of the acardiac twin. The vessel occlusive procedures available include fetoscopic cord ligation, laser coagulation, bipolar cord cauterization, ablation using radiofrequency or with absolute alcohol, and selective delivery of acardiac 
twin. Short-term outcome studies generally report a survival of $80 \%-90 \%$ for the pump twin after these in utero coagulation/ablation procedures ${ }^{[12,13]}$.

The classically reported incidence of TRAP sequence is $1 / 35,000$ pregnancies ${ }^{[1,2,4,6,10-14]}$ and most of these cases occur in monozygotic twin gestations. Acardius in triplet gestations constitutes only $8 \%$ of all acardiac cases and there have been fewer than 20 such cases described in the literature thus far ${ }^{[8]}$. This equates to an incidence of acardius in triplet gestations of 1/438,600 pregnancies. This figure includes all cases of acardius in triplet gestations - those with one acardiac fetus and those with two acardiac fetuses. Of particular interest to these authors is the incidence of two acardiac fetuses in a triplet gestation, as in the case described here. According to Youssef et al. ${ }^{[15]}$, the incidence of monochorionic diamniotic triplet gestations is 1.6/100,000 pregnancies. With TRAP sequence affecting 1/35,000 pregnancies, a calculation can be made to determine the frequency of TRAP sequence in a monochorionic diamniotic pregnancy. As such, we have estimated that TRAP sequence in a triplet gestation with two affected acardiac fetuses would occur in 1 of 4.6 billion pregnancies. We acknowledge that this estimation is an academic excise in which there could be other ways to arrive at such a number; nonetheless, we expect the same result with TRAP sequence in a triplet gestation being an exceedingly rare event.

The frequency of TRAP sequence, however, may theoretically increase in the future given the advancements in assisted reproductive technology and the resulting increase in the number of twin gestations ${ }^{[16]}$. Physicians must therefore be aware of this rare complication and emphasis should be placed on early US diagnosis to allow for prompt treatment, prognostic purposes, and for monitoring the pump fetus. Treatment options are evolving and continue to be updated in the literature as treating physicians gain experience and knowledge with the success and outcomes.

\section{References}

[1] Ventura W, Nazario C, Ventura J. Triplet pregnancy complicated by two acardiac fetuses. Ultrasound Obstet Gynecol. 2011; 38: 360-5. PMid:21425197 http://dx.doi.org/10.1002/uog.9001

[2] Cavoretto P, Serafini A, Valsecchi L, et al. Early diagnosis, follow-up, and prenatal treatment of a case of TRAP sequence occurring in a dichorionic triamniotic triplet pregnancy. J Clin Ultrasound. 2009; 37: 350-3. PMid:19444901 http://dx.doi.org/10.1002/jcu.20583

[3] Rohilla M, Chopra S, Suri V, et al. Acardiac-acephalus twins: a report of 2 cases and review of literature. Medscape J Med. 2008; 10: 200. PMid:18924652

[4] Sepulveda W, Wong AE, Bustos JC, et al. Acardiac fetus complicating a triplet pregnancy: management and outcome. Prenat Diagn. 2009; 29: 794-9. PMid:19449324 http://dx.doi.org/10.1002/pd.2291

[5] Alderman B. Foetus acardius amorphus. Postgrad Med J. 1973; 49: 102-5. PMid:4729183

[6] Sanjaghsaz H, Bayram MO, Qureshi F. Twin reversed arterial perfusion sequence in conjoined, acardiac, acephalic twins associated with a normal triplet. J Reprod Med. 1998; 43: 1046-50. PMid:9883409

[7] Benirschke K, des Roches Harper V. The acardiac anomaly. Teratology. 1977; 15: 311-6. PMid:560726

[8] Dahiya P, Agarwal U, Sangwan K, et al. Antenatal diagnosis of twin-reversed arterial perfusion sequence (acardiac amorphous) in a triplet pregnancy: case report. Arch Gynecol Obstet. 2003; 269: 147-8. PMid:12750923

http://dx.doi.org/10.1007/s00404-002-0421-5

[9] Bolaji II, Mortimer G, Meehan FP, et al. Acardius in a triplet pregnancy: cytogenetic and morphological profile. Acta Genet Med Gemellol (Roma). 1992; 41: 27-32.

[10] Prasad RHS, Prasad TR, Kumar KD. TRAP Sequence - An Interesting Entity in Twins. J Clin Imaging Sci. $2012 ; 2: 56$. PMid:23230538 http://dx.doi.org/10.4103/2156-7514.100997

[11] Wong AE, Sepulveda W. Acardiac anomaly: current issues in prenatal assessment and treatment. Prenat Diagn. 2005; 25: 796-806. PMid:16170844 http://dx.doi.org/10.1002/pd.1269

[12] Cabassa P, Fichera A, Prefumo F, et al. The use of radiofrequency in the treatment of twin reversed arterial perfusion sequence: a case series and review of the literature. Eur J Obstet Gynecol Reprod Biol. 2013; 166: 127-32. PMid:23122031 http://dx.doi.org/10.1016/j.ejogrb.2012.10.009

[13] Pagani G, D’Antonio F, Khalil A, et al. Intrafetal laser treatment for twin reversed arterial perfusion sequence: cohort study and meta-analysis. Ultrasound Obstet Gynecol. 2013; 42: 6-14. PMid:23640771 http://dx.doi.org/10.1002/uog.12495 
[14] Van Allen ML, Smith DW, Shepard TH. Twin reversed arterial perfusion (TRAP) sequence: A study of 14 twin pregnancies with acardius. Semin Perinatol. 1983; 7: 285-93. PMid:6658475

[15] Youssef A, Milano V, Pilu G, et al. Three-dimensional sonograph of a monochorionic diamniotic triplet pregnancy. J Clin Ultrasound. 2012; 40: 227-30. PMid:21688271 http://dx.doi.org/10.1002/jcu.20852

[16] Skiadas CC, Missmer SA, Benson CB, et al. Risk factors associated with pregnancies containing a monochorionic pair following assisted reproductive technologies. Hum Reprod. 2008; 23: 1366-71. PMid:18378561 http://dx.doi.org/10.1093/humrep/den045 